\title{
Planning and developing services for diabetic retinopathy in Sub-Saharan Africa
}

\author{
Sophie Poore ${ }^{1, *}$, Allen Foster ${ }^{2}$, Marcia Zondervan ${ }^{3}$, Karl Blanchet ${ }^{2}$
}

\begin{abstract}
Background: Over the past few decades diabetes has emerged as an important non-communicable disease in SubSaharan Africa (SSA). Sight loss from Diabetic Retinopathy (DR) can be prevented with screening and early treatment. The objective of this paper is to outline the required actions and considerations in the planning and development of DR screening services.

Methods: A multiple-case study approach was used to analyse five DR screening services in Botswana, Ghana, Tanzania and Zambia. Cases included: two regional screening programmes, two hospital-based screening services and one nationwide screening service. Data was collected using qualitative methodologies including: document analysis, indepth interviews and observation. The World Health Organization (WHO) Health Systems Framework was adopted as the conceptual framework for analysis.

Results: Planning for a sustainable and integrated DR screening programme demanded a health systems approach. Collaboration with representatives from a variety of ministerial departments and professional bodies was required. Evolution of DR screening services may occur in a variety of ways including: increasing geographical coverage, integration into the general healthcare system, and stepwise progression from a passive, opportunistic service to one that systematically and proactively seeks to prevent DR. Lessons learned from the implementation of cervical cancer prevention programmes in resource-poor settings may assist the development of DR programmes in similar settings. Conclusion: To promote good planning of DR screening services and ensure limited resources are used effectively, there is a need to learn from screening programmes in other medical specialities and a need to share experiences between newly-developing DR programmes in resource-poor countries. The WHO Health Systems Framework presents an invaluable tool to ensure a systematic approach to planning DR screening services.

Keywords: Diabetic Retinopathy (DR), Health Systems, Service Planning, Screening Programme, Sub-Saharan Africa (SSA)

Copyright: ( 2015 by Kerman University of Medical Sciences

Citation: Poore S, Foster A, Zondervan M, Blanchet K. Planning and developing services for diabetic retinopathy in Sub-Saharan Africa. Int J Health Policy Manag 2015; 4: 19-28. doi: 10.15171/ijhpm.2015.04
\end{abstract}

\section{Article History:}

Received: 21 September 2014 Accepted: 12 December 2014 ePublished: 16 December 2014

\section{*Correspondence to:}

Sophie Poore

Email: sophiepoore@doctors.org.uk

\section{Key Messages}

Implications for policy makers

- Initial steps include assessing the need and priority for a Diabetic Retinopathy (DR) screening service and identification of a clinical lead.

- Planning must include consideration of all elements of the World Health Organization (WHO) Health Systems Framework, workload estimates, current staffing and local geography.

- Collaboration with endocrinologists is essential and discussions with various high-level stakeholders must occur, including:

- National diabetes associations

- National informatics departments

- Non-communicable disease and public health departments

- National Committee for the Prevention of Blindness.

- The curriculum of the eye care workforce must reflect the demands of the diabetes epidemic and new roles must receive official recognition.

- Prior to equipment procurement there must be discussion with biomedical engineers, and arrangement of comprehensive maintenance agreements with manufactures.

- The service delivery approach (vertical vs integrated, static vs outreach) should be that which reduces multiple appointments for patients and administrative burden to providers.

Implications for public

Rapid urbanisation and changes in lifestyle are making diabetes increasingly common in Sub-Saharan Africa (SSA). Diabetic eye disease can cause sight loss and screening programmes allow the disease to be detected and treated in its early, less severe stage. This research examines five screening programmes that have recently been set-up in SSA and looks at the problems they encountered and how they solved them. The results of this research will alert policymakers and programme managers to important considerations when they set-up screening services or want to expand their existing services. This research hopes to benefit diabetics in SSA as it will promote the development of user-friendly services. Additionally, the sharing of lessons-learnt will prevent unwise spending of limited public funds. 


\section{Introduction}

Diabetes is an increasing cause of morbidity and premature mortality in Sub-Saharan Africa (SSA) (1). The main sightthreatening complication of diabetes is Diabetic Retinopathy (DR) which is a disease of the retina, situated at the back of the eye (2). The natural history of DR and the availability of effective screening and treatment approaches, justify the development of DR prevention programs. Retinal screening examinations are recommended by the International Council of Ophthalmology (ICO) on a yearly or two-yearly basis (3). Diabetes is a chronic, multi-system disease requiring multi-disciplinary management and continuity of care (2). In order to provide well-coordinated and well-documented diabetic care, considerable strengthening and reorganisation of the health system is needed as the health system in SSA is more accustomed to treating episodic health events (such as infectious diseases or trauma) $(2,4)$.

Neither guidance nor documented experiences exist concerning establishing DR screening services in developing countries. However, it is possible that lessons learned from cervical cancer prevention programmes in resource-poor settings can assist the development of DR programmes. Poor performance of cervical cancer prevention programs in developing countries is reported most frequently to be a consequence of inadequate planning and lack of systems for continuous monitoring and evaluation - irrespective of the screening test or treatment methods used (5).

This paper will report on the planning, implementation and development of five DR screening programmes in Botswana, Ghana, Tanzania and Zambia. Each programme is supported by a VISION 2020 LINK, these are long-term partnerships between eye departments in Africa and the UK that promote transfer of skills and knowledge. Relevant, practical and transferable information will be shared as derived from analysis of the lessons learned during programme planning and implementation.

Part one is a discussion of the health system considerations pertinent to planning a DR prevention programme. The discussion will be framed using the World Health Organization (WHO) Health Systems Framework or 'building-blocks' (Figure 1).

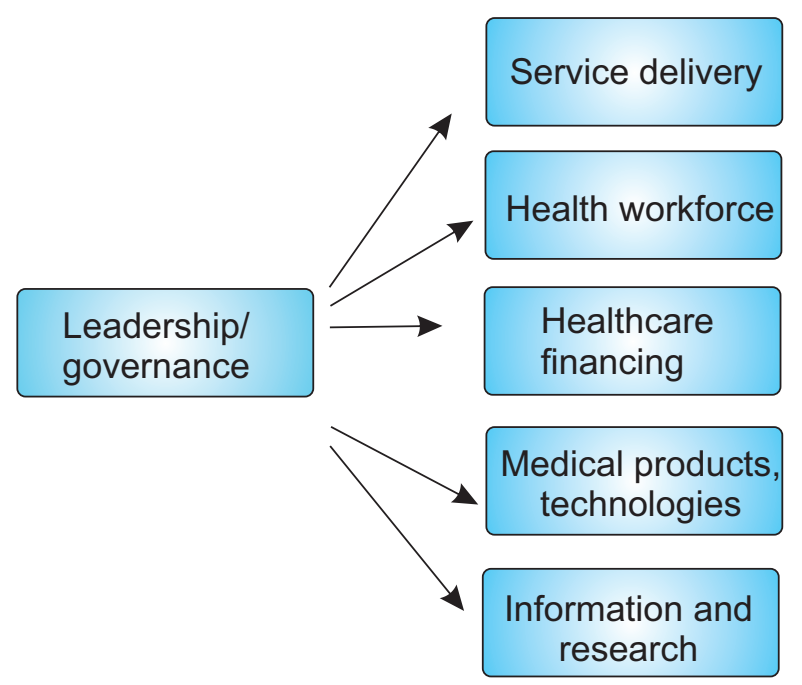

Figure 1. WHO Health Systems Framework (6). Diagram adapted from Blanchet and Patel (7).
Five steps towards implementing and developing a DR screening service are discussed in part two of the article.

\section{Methods}

Case study methodology

Multiple case study methodology was used to analyse five DR screening services (Table 1) in four SSA countries (Figure 2). Case study design was used, which is an approach to research appropriate for understanding and interpreting complex causal links in natural setting interventions (8).

\section{Data collection}

Case study methodology relies on 'methodological triangulation' which is the collection of data from multiple sources of evidence. This supports the principle of case study research that phenomena can be viewed and explored from multiple perspectives (9).

Qualitative methods of data collection were employed, including: literature review, semi-structured interviews and participant observation. Data collection was undertaken between June-September 2013.

\section{Literature review}

Review of the scientific and grey literature was conducted.

\section{Document analysis}

A document analysis is a qualitative research method that involves the study of documents to understand their content and to interpret their deeper meanings as revealed by their

Table 1. Case studies

\begin{tabular}{ll}
\hline Programme & Description \\
\hline $\begin{array}{l}\text { Kilimanjaro Diabetes Project } \\
\text { (KDP), Tanzania }\end{array}$ & Regional-level, outreach screening \\
$\begin{array}{l}\text { Copperbelt DR Screening } \\
\text { Programme, Zambia }\end{array}$ & Regional-level, outreach screening \\
$\begin{array}{l}\text { Muhimbili Hospital, Dar es Salaam, } \\
\text { Tanzania } \\
\text { Korle Bu Hospital, Accra, Ghana }\end{array}$ & Hospital eye department-based \\
Project Pono Letlotlo, Botswana & Nationwide screening programme \\
\hline
\end{tabular}

DR= Diabetic Retinopathy

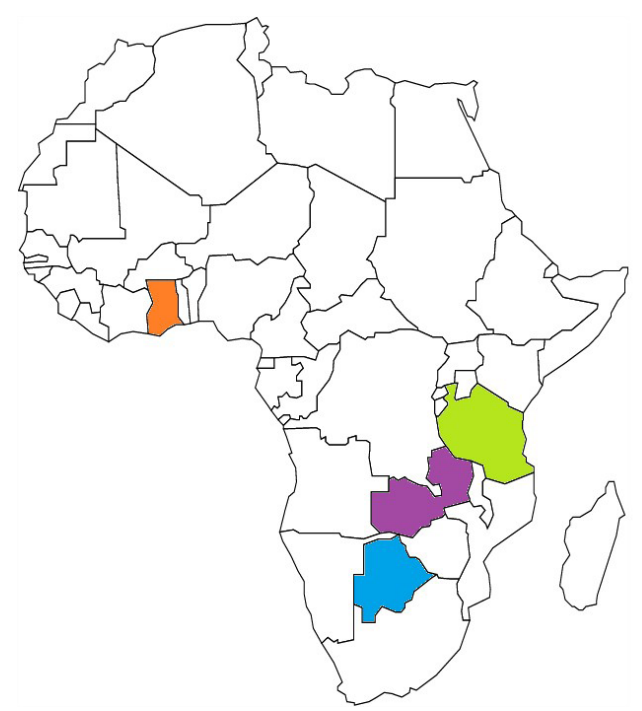

Figure 2. Location of case studies 
style and coverage (10). Documents analysed included: VISION2020 LINK documentation, national strategic plans (eye care, diabetes and non-communicable diseases), clinical practice guidelines and Non-Governmental Organisation (NGO) reports.

\section{In-depth interviews}

Fifty-four individuals involved in the delivery and planning of DR programmes were interviewed (Table 2). Participants were selected via the snowball technique whereby interviewees recommend professional acquaintances meeting the sampling criteria. In-depth interviewing allows the respondent to recount stories in their own words with prompting by the interviewer (10). This qualitative technique is of particular use when detailed information about new issues is required (11). In this study the nature of the prompting questions depended on the interviewee's area of expertise. Interviews were conducted at a location convenient for the interviewee and the average duration was 23 minutes per interviewee. Patients were not interviewed which is a limitation of this study.

\section{Observation}

The objective of field observation is to collect data in a 'natural setting. The researcher spent approximately five days in each setting during which DR prevention activities and planning meetings were observed.

\section{Data analysis}

Cross-checking across data sets (data triangulation) was performed to uncover inconsistencies and reveal recurrent themes. Where data inconsistencies were found, further interviews were conducted. Convergence of data enhances the validity of the findings $(9,10)$. The WHO Health System Framework (Figure 1) was used as the analytical framework.

\section{Results and Discussion}

Part one: health systems approach to planning Diabetic Retinopathy services

1) Leadership/governance

Decision to start a screening programme

In Botswana, a DR prevention programme was deemed

Table 2. Number and role of interviewees

\begin{tabular}{lc}
\hline Interviewee & Number \\
\hline National Eye Care Coordinator/Deputy & 5 \\
UK VISION 2020 LINK volunteer & 7 \\
\hline Ophthalmologist & 12 \\
\hline Endocrinologist & 3 \\
\hline Public health physician & 1 \\
Resident ophthalmologist & 3 \\
Ophthalmic nurse & 8 \\
\hline Programme manager & 2 \\
\hline Ophthalmic imaging technician & 3 \\
\hline Optometrist & 2 \\
\hline Administrator & 3 \\
Diabetic association manager & 2 \\
Biomedical engineer & 3 \\
\hline Total & 54 \\
\hline
\end{tabular}

necessary subsequent to an epidemiological study that found DR was the second leading cause of blindness after cataract (20\% and $46.9 \%$ respectively) (12).

In all other programmes under investigation, initiation of programmes arose largely from ophthalmologists with specialist interest in retinal diseases (and in the case of Ghana, an endocrinologist) who encountered a high patient load of late-stage DR and saw screening as a natural solution.

Sufficient public health justification for screening, based on scientific evidence, is a strong tool to garner political commitment for screening programs, particularly in an environment of competing priorities. Despite the lack of local data, there is sufficient evidence available for extrapolation that can demonstrate the likely scale of the problem, and assist projections in morbidity and blindness reduction.

DR screening programmes are proven to be cost-effective interventions in high-income settings, (13) however, this is yet to be determined in African settings (2). It is important to note that cervical cancer programmes benefit from large volumes of evidence, especially economic analyses and modelling studies, that informed government decisions to commence cervical cancer screening $(14,15)$.

It is recognised that if screening tests are accessible to and affordable to the population, then opportunistic case detection occurs irrespective of evidence and policy (16). If screening begins haphazardly, without guidelines, standards or structure, an inequitable and inefficient system can arise and direct patient harm might ensue (16).

\section{Leadership and management}

In SSA, ophthalmologists with specialist training in retinal diseases are few in number hence concern might exist that self-identifying leaders will not emerge. Finding a retinal ophthalmologist to adopt the role of clinical lead may involve an active search (such was the case in Botswana) or opening up the role to endocrinologists (as is sometimes practiced in the UK).

Multidisciplinary planning and management was observed in the Kilimanjaro Diabetes Programme (KDP) with an endocrinologist, programme manager, database designer and ophthalmologists on the management committee. Inclusion of the endocrinologist brought significant benefits including promoting interdepartmental relationships and facilitating linkages with other general/diabetic doctors in the region, national diabetes networks and international funding bodies.

\section{Governance}

All countries under investigation confirmed political commitment through recognising the importance of DR within the Ministry of Health $(\mathrm{MoH})$ National Eye Care Plan. In order for sustainable and integrated services, it appeared that attention to the function of governance within all health system building blocks was key (Figure 1). This was particularly the case in Botswana, where in order to plan the national programme, a series of high-level stakeholders were engaged (Table 3 ).

\section{2) Service delivery}

Various methods of delivering the screening test were selected as outlined in Table 4. Advantages and disadvantages of the 
Table 3. List of stakeholders engaged during the planning process for Botswana's national screening programme

\begin{tabular}{|c|c|}
\hline Stakeholder & Involvement \\
\hline MoH National Committee for the Prevention of Blindness & $\begin{array}{l}\text { Continuous engagement with this department allowed alignment with the national eye care } \\
\text { strategy. }\end{array}$ \\
\hline MoH Non-Communicable Disease Department & Identified synergies between strategies for DR and diabetes. \\
\hline MoH Head of Clinical Services & Negotiations regarding staff transfers. \\
\hline MoH Chief Biomedical Engineer & Discussed new equipment and engineer training needs. \\
\hline MoH Chief Pharmacist & $\begin{array}{l}\text { Discussed drug shortages at the health facility level to identify bottlenecks in procurement. } \\
\text { Analysis of national drug formulary. }\end{array}$ \\
\hline MoH Chief Information Technologist & $\begin{array}{l}\text { Requirements for a DR screening module were presented to the developers of the } \mathrm{MoH} \\
\text { electronic patient record system. }\end{array}$ \\
\hline Medical School of Botswana & Opportunities presented for research within the DR programme. \\
\hline Higher Education Institutions & Development of an accredited grading course. \\
\hline Diabetic Association of Botswana & Leaders and members were sensitised to the DR screening programme. \\
\hline
\end{tabular}

$\mathrm{MoH}=$ Ministry of Health; DR= Diabetic Retinopathy

Table 4. Mode of service delivery

\begin{tabular}{|c|c|}
\hline Programme & Service delivery \\
\hline Korle Bu Hospital, Accra, Ghana & Static screening in diabetic clinic by ophthalmoscopy \\
\hline Muhimbili Hospital, Dar es Salaam, Tanzania & Static screening in eye department by slit-lamp biomicroscopy \\
\hline Kilimanjaro Diabetes Project (KDP), Tanzania & Screening outreaches using fundus camera \\
\hline Copperbelt DR Screening Programme, Zambia & Screening outreaches using fundus camera \\
\hline Project Pono Letlotlo, Botswana & $\begin{array}{l}\text { Mixed methods including: static fundus camera in diabetic clinic, transporting patients to a central fundus } \\
\text { camera, ophthalmoscopy }\end{array}$ \\
\hline
\end{tabular}

available tests are available on the ICO Guidelines for Diabetic Eye Care (3).

\section{Vertical vs integrated}

One of the key planning decisions influencing service delivery of cervical cancer screening programmes is whether programmes are vertical, or integrated into other health services (5). In vertical or stand-alone programmes, the workforce, infrastructure and informatics are devoted to only one service $(5,17)$. Fully integrated services involve managerial or operational changes to health systems to create permanent services that are fully merged with multifunctional healthcare delivery (17).

Different extents of integration were observed in the programmes investigated. Various factors were seen to influence the decision of whether to integrate DR screening programmes into diabetes care and/or ophthalmology, such as: specialty of the clinical lead, orientation of the funding body, and available human and material resources. Table 5 shows the strengths and limitations of three different extremes of integration.

\section{Static vs outreach screening site}

Various models of service delivery are applicable to settings which are different in terms of their geography, resource levels and health facility and staffing arrangements. DR screening can be delivered using static or outreach sites, or a combination (Table 6). Static services are those that are provided regularly at an established facility. Outreach services use a variety of facilities (healthcare or non-healthcare) and bring in the staff, equipment and supplies for a limited time.

\section{Screening services-based in the eye department}

The success of eye department-based services appeared to be related to the extent of professional integration between the diabetes and eye departments. The term 'professional integration' refers to the act of collaboration between health professions or specialities to provide joined-up services (18). Challenges with providing joined-up services arose firstly when endocrinologists were poorly informed of the services being provided by the eye department.

'They [eye department] started something and doing the lasers, but with the problem with the linking of information to the [endocrinology] consultant, you don't know what is happening, what they are offering' (Informant 28).

Secondly, challenges arose when the endocrinologist was unaware of a patients screening status.

'There is no separate file where you can see if a patient has been screened or not. You have to rely on when you see the patient. Or at least in that clinic it would be good to know how many patients [have attended screening]; is it 20\%, 30\% or $40 \%$ ?' (Informant 28).

A final challenge facing this model of service delivery was that patients would find it difficult to reach the eye department, patients would dislike joining a further a queue at the eye department, and finally same-day screening appointments were not always available at the eye department.

'Patients have to move and you can imagine the distance [...] at least the appointments can be given at the same place' (Informant 28).

However, successful models of eye department-based screening were observed in Botswana. One clinic found that providing a reliable, weekly service was successful.

'It's working well because it's an open-system that they know every Friday is diabetic [retinopathy screening] clinic day so if a patient maybe fails to come this Friday, other Fridays they can still turn up' (Informant 1).

In a second clinic in Botswana, strict structuring of patient 
Table 5. Strengths and limitations of vertical and integrated programmes

\begin{tabular}{|c|c|c|c|}
\hline & Vertical & Integrated into diabetes care & Integrated into ophthalmology \\
\hline Strengths & $\begin{array}{l}\text { - Higher commitment to DR } \\
\text { prevention objectives } \\
\text { - Staff roles and responsibilities } \\
\text { clearly defined } \\
\text { - Fewer staff need training }\end{array}$ & $\begin{array}{l}\text { Part of a one-stop service for } \\
\text { diabetic complications } \\
\text { - Easy access to target population } \\
\text { so less need for a call/recall } \\
\text { system } \\
\text { - Easy access to diabetic register }\end{array}$ & $\begin{array}{l}\text { - On-site referrals if screen positive } \\
\text { - Other causes of vision loss can be explored } \\
\text { - Screening equipment can be used for other } \\
\text { clinical requirements }\end{array}$ \\
\hline Limitations & $\begin{array}{l}\text { - Higher cost for health system } \\
\text { as no sharing of facilities or } \\
\text { equipment } \\
\text { - Logistical burden to the client } \\
\text { for screening and referrals }\end{array}$ & $\begin{array}{l}\text { - New staff will be required } \\
\text { - Patients to travel to referral } \\
\text { appointment } \\
\text { - Blurry vision for other } \\
\text { appointments on this day due to } \\
\text { dilation drops }\end{array}$ & $\begin{array}{l}\text { - May excessively increase workload } \\
\text { - Patients may only present upon deterioration of } \\
\text { vision } \\
\text { - Competing priorities (prevention seen as less } \\
\text { urgent than treatment) } \\
\text { - Have to specifically travel to screening } \\
\text { appointment }\end{array}$ \\
\hline
\end{tabular}

DR= Diabetic Retinopathy

Table 6. Strengths and limitations of static and outreach methods of service delivery

\begin{tabular}{|c|c|c|}
\hline & Static & Outreach \\
\hline Strengths & $\begin{array}{l}\text { - Easy to book and attend referral appointments if screening held } \\
\text { in eye department } \\
\text { - If poor view of fundus is obtained by screening test, alternative } \\
\text { equipment may be available to achieve a better view } \\
\text { - Screening is convenient for patient if held in diabetic clinic }\end{array}$ & $\begin{array}{l}\text { - Higher coverage as screening is taken to the patient } \\
\text { - Raises awareness amongst the community }\end{array}$ \\
\hline Limitations & $\begin{array}{l}\text { - Patients not attending diabetic clinic may not benefit from } \\
\text { service } \\
\text { - On-going efforts required to promote services and provide } \\
\text { transport to static service } \\
\text { - Patients may only travel for screening if vision is already } \\
\text { impaired }\end{array}$ & $\begin{array}{l}\text { - Patients without the means to travel to treatment facilities } \\
\text { - } \text { will be screened, resulting in a poor treatment uptake rate } \\
\text { grading } \\
\text { - Image transfer systems may be required } \\
\text { - Fundus cameras may break if taken over rough terrain } \\
\text { - Cost and time for mobile team } \\
\text { - Requires intensive planning }\end{array}$ \\
\hline
\end{tabular}

flow between the ophthalmic and diabetes departments, in combination with good 'nurse-to-nurse' communication, helped create a joined-up service.

'The nurse who conducts the diabetic clinic she tells patient; 'You are not supposed to come to your diabetes check, before you [must] pass by the eye clinic for the retina check" (Informant 3).

Screening services-based in the diabetes clinics

In Ghana and a further clinic in Botswana, DR screening was included as a routine part of the holistic diabetic check. The predominant problem facing this model of service delivery was that patients with positive screening tests frequently failed to attend the eye department. Patients were deterred by the prospect of long queues after having waiting in lengthy queues in the diabetic clinic. Transfer of patient records between departments also inhibited same-day services.

\section{Screening outreach services}

The KDP and Copperbelt programmes operated outreach models, undertaking DR screening at the patients' local clinic with fundus photography. Both programmes achieved very high screening rates. The KDP screened $90 \%$ of the 3,175 patients registered with the KDP over a period of just over two years (AusAid Project Proposal 2012-4. Unpublished data, 2012). Within a period of five months, the Copperbelt screened 1,233 patients (CBM Narrative Monitoring Report. Unpublished data, 2013).
Uptake of referrals to the eye department after a positive screening test was the main challenge faced by these programmes.

'The most pressing question for us; why do so many patients not come? The whole thing is in vain if they don't come for treatment' (Informant 11).

Misconceptions about screening may cause patient attrition as illustrated by one interviewee.

'The issue was them coming over for treatment. I think what they had in mind was everything being done at the screening point' (Informant 30).

Additionally, the community was reported to hold myths about the eye hospital, affecting the uptake of referrals.

'They come for screening, then they go home and the people at home discourage them from coming they will tell them when you go there that's it, the sight is gone' (Informant 30 ). Steps were taken to encourage patients to attend including: phone call reminders, bus transportation and research into barriers to uptake of referrals.

\section{Call/recall and referral systems}

Due to lack of systems to facilitate call/recall (poor mobile phone coverage, poor literacy, lack of postal systems, lack of diabetic registers), community education schemes were essential and highly effective in attracting patients to screening. For example in the Copperbelt, where no diabetic register existed, patients were invited to screening through the provision of information and education to the diabetic 
clinics and community. The high screening rate achieved by the Copperbelt demonstrates that services can still thrive where resources are not available to start registers and formal call/recall systems.

\section{3) Health workforce \\ Screening needs and options}

Different cadres adopted the role of screeners/graders in the various programmes. The strengths and limitations of each are summarised in Table 7 . With adequate training non-medical staff were able to competently screen and grade. The main challenge facing cadres less accustomed to image interpretation was the infrequent opportunities they were given to practice their skills. It appeared to be a tradeoff between having a small number of dedicated graders and having numerous graders allowing large throughput at outreach but limited grading episodes in between.

'[In the UK] they explained to us you have to be doing it every day so that you fine tune. But here you are this side, you are that side, and it's a bit of a challenge' (Informant 39). A similar issue was abated in the UK by a recommended annual minimum of 1,000 image sets for non-optometrist/ ophthalmologist graders (19).

Due to the need for multiple treatment and follow-up episodes, screening programmes can exponentially increase the workload. An essential element of planning a DR programme is ensuring sufficient health workers are trained to treat DR. Workload estimation in SSA was challenged by the lack of diabetic registers and epidemiological data. A solution in the Copperbelt was the use of pharmacy data of dispensed diabetic medication to gain regional estimates of known diabetics from which to base further calculations. Additional ophthalmologists trained in the diagnosis and management of DR are required and Burgess et al. (2) provide recommendations to improve training in retinal diseases in SSA including: increasing the total number of ophthalmologists to allow increased sub-specialisation, and developing centres of excellence for retinal care and subspecialist training. Task shifting is also likely to be required and is already underway in some situations e.g. in the Copperbelt, where an ophthalmic nurse was being trained to provide laser treatment.

\section{Planning for workforce sustainability}

1. Staff Transfers: Transfer of staff by the $\mathrm{MoH}$ is a common phenomenon and posed a threat to the newly emerging programmes. In order to ensure the programmes were not jeopardised and specialist training not wasted, various solutions were sought: specialised training was focused on personnel employed under the eye unit, agreements formed with the $\mathrm{MoH}$ and DR services were placed in facilities with static staffing arrangements.

2. Responsive curriculum: The curriculum of many healthcare professionals must evolve to meet demands of the epidemic of diabetes. For example, in Tanzania the $\mathrm{MoH}$ National Eye Care Plan strives to ensure a responsive biomedical engineer curriculum through submitting new ophthalmic equipment maintenance requirements for inclusion in the undergraduate curriculum (20).

3. Licensing and recognition of new roles: Where task shifting or a broadening in scope of traditional roles was necessary in cervical cancer screening programmes, new roles were more readily recognised when decisions were made in conjunction with relevant professional organisations and licensing bodies (5). An example from eye care in Ghana, was that in order for slit-lamp examinations to be officially accepted into the skill-set of the ophthalmic nurse, approval had to be gained from the Nursing and Midwifery Council of Ghana.

In multiple programmes, DR screening programme staff were employed via NGO funding. To afford greater sustainability, newly created positions (such as programme manager, photographer etc.) are likely to require formal recognition to appear on the government payroll.

\section{4) Financing \\ Out of pocket expenditures}

In the majority of programmes, screening was free of charge or performed at a small fee and treatment would usually incur a cost to the patient. Exceptions to the rules were frequently reported.

\section{Insurance schemes}

In the context of the Ghanaian National Health Insurance

Table 7. Strengths and limitations of each cadre for screening/grading

\begin{tabular}{|c|c|c|c|c|}
\hline & Technician & Ophthalmic nurse & Optometrist & Ophthalmologist \\
\hline Strength & $\begin{array}{l}\text { - Good geographical coverage } \\
\text { - Able to maintain equipment } \\
\text { - Fewer competing clinical } \\
\text { demands }\end{array}$ & $\begin{array}{l}\text { - Good geographical } \\
\text { coverage } \\
\text { - Good counselling } \\
\text { skills } \\
\text { - If camera } \\
\text { breaks, can use } \\
\text { ophthalmoscope }\end{array}$ & $\begin{array}{l}\text { Experienced in use of } \\
\text { various ophthalmic } \\
\text { equipment }\end{array}$ & $\begin{array}{l}\text { - Can give immediate feedback of } \\
\text { screening test result } \\
\text { - Can screen and treat during same } \\
\text { appointment } \\
\text { - Equipped with skills and facilities } \\
\text { to visualise 'ungradable' images } \\
\text { - May be appropriate as a quality } \\
\text { control grader }\end{array}$ \\
\hline Limitation & $\begin{array}{l}\text { - } \text { Require training in grading } \\
\text { Immediate feedback of } \\
\text { screening test result may not } \\
\text { be possible unless further } \\
\text { grading and communication } \\
\text { competencies achieved. } \\
\text { - Quality assurance system may } \\
\text { be needed }\end{array}$ & $\begin{array}{l}\text { - Require training } \\
\text { in grading and } \\
\text { screening test } \\
\text { - Quality assurance } \\
\text { system may be } \\
\text { needed }\end{array}$ & $\begin{array}{l}\text { Poor geographical } \\
\text { coverage, but situated } \\
\text { in cities (where } \\
\text { diabetes predominates) } \\
\text { - Quality assurance } \\
\text { system may be needed }\end{array}$ & $\begin{array}{l}\text { - Poor geographical coverage, but } \\
\text { situated in cities (where diabetes } \\
\text { predominates) } \\
\text { - } \text { Expensive resource } \\
\text { - } \text { Residents were the graders for the } \\
\text { KDP and proved to be reliable, but } \\
\text { required financial incentives }\end{array}$ \\
\hline
\end{tabular}


Scheme (NHIS), an important preparatory step was to understand the minimum services covered by the scheme. The list of minimum services contained no mention of retinal detachment or laser treatment, furthermore, ophthalmic diagnostic drugs (e.g. dilating drops) are not covered by the NHIS (21).

\section{Government}

Government reimbursement for DR prevention services may be derived from different government departments to the majority of ophthalmic services. For example, in Ghana, diabetes and outreach services sit within the Public Health Directorate whereas eye care provision is under the remit of the Institutional Care Directorate, this is thought to contribute to the difficulty in accessing public health budgets for ophthalmic nurse outreaches (21).

\section{Donors}

The programmes under investigation were funded by varied NGOs, specialising in diabetes, ophthalmology or disability prevention. The orientation of the funding body reflected the scope of the programme.

A strong suggestion from the programme managers was that relationships with diabetic organisations should be formed as early as possible in the planning phase so that DR is not omitted from general diabetes projects and funding. Both DR programmes in Tanzania found that collaborating with the Tanzania Diabetic Association brought significant benefits, including involvement in general diabetes projects and easier connections with diabetic funding bodies.

\section{5) Medical products and technologies \\ Screening}

Fundus cameras were possessed by all programmes visited and used either for screening or diagnosis. Four out of the five programmes studied were impacted by malfunctioning cameras and repair was inhibited as:

- Engineers in SSA lack experience with fundus cameras;

- Manufacturer support was slow and problematic;

- Limited learning was gained from manufacturer visits;

- Access to required manufacturer manuals is restricted;

- Spare parts were hard to acquire.

It was reported that during procurement consideration was not given to: the technicians' familiarity with equipment, the ease of contacting the manufacture, the availability of spare parts, and frequently the equipment was without the necessary manuals.

'You are just called to fix it. When they were requesting you were not involved. Then when you get there you have no manual' (Informant 20).

Considerations prior to procurement and relevant areas for negotiation with the supplier may include: location of distributor, availability of a training package and comprehensiveness of the maintenance scheme.

\section{Treatment}

Anti-Vascular Endothelial Growth Factor (anti-VEGF) injections were used in some centres, however, laser therapy is recommended as a more economic treatment option as running costs are lower $(2,3)$. Despite this, anti-VEGF is important in the therapeutic armamentarium for DR and part of the planning process in Botswana was to consult the $\mathrm{MoH}$ chief pharmacist and analyse the drug formulary to identify the available drug preparations.

\section{6) Informatics and research \\ Database development}

DR databases were a significant enabling feature in both the practical operation and quality assurance of the programmes. The KDP demonstrated the wider benefits that a database conveys: the research capacity of the diabetes and eye departments was increased, reporting to their funder was made easier as the required programme statistics were embedded into the database, and finally it allowed detection of geographic and demographic inequalities in service uptake. Future research plans and reporting requirements should be considered at the database development phase.

The creation of a DR screening database is challenged in lowresource settings by the lack of diabetic registers. Different approaches to developing a database were observed as displayed in Table 8 .

The sourcing of patients differed according to the level of professional integration between diabetes and eye departments. Screening programmes working in close conjunction with the diabetes department had good access to diabetic patients through this route; screening programmes with a less integrated approach added patients to their database at the point of screening. In Botswana, embedding

Table 8. Scope, coverage and development of four DR screening programme databases

\begin{tabular}{|c|c|c|c|c|}
\hline Programme & Type & Main scope of data & Coverage & Development process \\
\hline KDP & $\begin{array}{l}\text { Microsoft } \\
\text { Access }\end{array}$ & $\begin{array}{l}\text { Diabetes register, } \\
\text { DR screening }\end{array}$ & Regional & $\begin{array}{l}\text { Patients were sourced through their attendance at diabetes clinics. } \\
\text { Database was created by an ophthalmologist, maintained by data } \\
\text { entry clerks. }\end{array}$ \\
\hline $\begin{array}{l}\text { Copperbelt DR } \\
\text { Screening Programme, } \\
\text { Zambia }\end{array}$ & $\begin{array}{l}\text { Microsoft } \\
\text { Excel }\end{array}$ & $\begin{array}{l}\text { DR screening and } \\
\text { treatment }\end{array}$ & Regional & $\begin{array}{l}\text { Created by the clinical staff through registering each patient attending } \\
\text { the DR screening outreaches. }\end{array}$ \\
\hline $\begin{array}{l}\text { Project Pono Letlotlo, } \\
\text { Botswana (plan) }\end{array}$ & EHR & $\begin{array}{l}\text { Numerous clinical } \\
\text { specialties }\end{array}$ & $\begin{array}{l}\text { National } \\
\text { coverage } \\
\text { anticipated }\end{array}$ & $\begin{array}{l}\text { The MoH of Botswana is supporting the development of a national } \\
\text { electronic system for clinical record keeping. Inclusion of a DR } \\
\text { screening module was requested by the planning team. }\end{array}$ \\
\hline $\begin{array}{l}\text { Korle Bu Hospital, } \\
\text { Accra, Ghana }\end{array}$ & $\begin{array}{l}\text { Paper-based/ } \\
\text { Microsoft } \\
\text { Excel }\end{array}$ & $\begin{array}{l}\text { DR screening, } \\
\text { insurance, other } \\
\text { eye diseases, BMI }\end{array}$ & $\begin{array}{l}\text { National } \\
\text { Diabetes } \\
\text { Centre, Accra }\end{array}$ & $\begin{array}{l}\text { A patient ledger is maintained by the ophthalmic nurses stationed in } \\
\text { the diabetic centre. The data is also transferred to Microsoft Excel. }\end{array}$ \\
\hline
\end{tabular}

$\mathrm{DR}=$ Diabetic Retinopathy; KDP= Kilimanjaro Diabetes Programme; EHR= Electronic Health Record; BMI= Body Mass Index; MoH= Ministry of Health 
DR screening into the national Electronic Health Record (EHR) will facilitate integration into the general health system. The opportunity to be part of the national EHR was enabled through planning at the $\mathrm{MoH}$ level.

Diabetes is a laboratory diagnosis, and disease monitoring is also by laboratory tests. Laboratory data may present a valuable resource in workload estimation, patient tracking and database creation. The Ghana National Diabetes Centre is in the process of developing a EHR for diabetic patients and laboratory data appeared to play an essential role in both the needs assessment and in creation of the database through merging clinical visit data with laboratory data (22).

\section{Image transfer}

In programmes using fundus photography as the screening test, multiple-level grading of images may be adopted whereby either all images, or a proportion of images are reassessed for quality purposes. Single-level grading is also an option however it requires highly-skilled graders and may be challenging in the outreach environment (19).

Multiple-level grading is facilitated by image transfer systems, however, in the programmes studied, physical passing of the laptop or transfer between hard-drives was the only mechanism for image sharing. Improvement in this domain is likely to confer benefits to other specialities in which monitoring of images over time is required, strengthening the case for improved health informatics.

\section{Part two: implementation and development of services}

Four main approaches by which services evolve are outlined below.

\section{Stepwise approach - opportunistic to systematic}

Screening services emanating from hospital facilities were seen to take a stepwise approach to development. Table 9 demonstrates a five step approach towards developing a DR screening service and Table 10 shows the stage of development of the programmes under investigation.

Progression through the steps outlined in Table 10 incrementally increases the patient load and permits a gradual strengthening of eye department treatment capacity. At each step the accessibility of screening is improved and the service is moved from opportunistic to systematic. Opportunistic screening is the provision of a screening test upon presentation to a healthcare provider for reasons unrelated to that disease (24). Systematic screening encompasses a series of planned

Table 9. Stepwise approach towards implementing and developing a DR screening service. This model was informed both by findings from the field and by the four step approach towards development of systematic screening programs for sight-threatening DR proposed by Scanlon et al. (23).

\begin{aligned} & \hline Five steps towards implementing a DR screening service \\ & \hline 1) Diagnose and treat cases in the eye clinic \\ & 2) Screen all diabetes patients at hospital diabetes clinic \\ & 3) Create diabetes register and call for eye screening \\ & 4) Identify undiagnosed diabetes/DR in the community \\ & 5) National DR programme with education \\ & \hline\end{aligned}

$\mathrm{DR}=$ Diabetic Retinopathy
Table 10. Stage of development of DR programme (correct as of June/July 2013)

\begin{tabular}{ll}
\hline Programme & $\begin{array}{l}\text { Stage of } \\
\text { Development }\end{array}$ \\
\hline Muhimbili Hospital, Dar es Salaam, Tanzania & 1 \\
Korle Bu Hospital, Accra, Ghana & 2 \\
Project Pono Letlotlo, Botswana (some centres) & 2 \\
Copperbelt DR Screening Programme, Zambia & 3 \\
Kilimanjaro Diabetes Project (KDP), Tanzania & 3 and 4 \\
\hline
\end{tabular}

$\mathrm{DR}=$ Diabetic Retinopathy

activities including actively identifying the screening population, providing the screening test, communicating the results, treatment and quality assurance $(16,24)$.

This model targets those who attend the hospital facilities before offering screening to the community, this allows patients with the poorest control and greatest need to be targeted first. Both Korle Bu Hospital in Ghana and Muhimbili Hospital in Tanzania began DR screening by offering services to patients seen in the hospital diabetic clinic. This appeared to be a logical first-step for two reasons. Firstly, patients require a referral to be seen in hospital diabetes clinics and are therefore a 'high-risk' group of diabetics who are most likely to possess risk factors for developing DR. Secondly, these patients may be more likely to attend follow-up and treatment as they have already demonstrated that they are users of hospital services.

In contrast, patients attending from community advertising, anecdotally had less advanced disease.

'Big, big numbers of patients come from the radio advert. They are at the stage where retinopathy is very stable' (Informant 26).

Transitioning between step 1 and step 2 was challenged by poor professional integration between the eye and diabetic clinics and by the issue of fundus camera ownership preventing transfer from the eye department to the diabetic clinic.

Steps 1-4 were methodically progressed through in the Kilimanjaro region. Whist screening was occurring in the diabetic clinic, a prospective intervention study was performed. The intervention involved the placement of a dedicated nurse counselor in the diabetic clinic to promote DR screening, which increased screening uptake from $27 \%$ to $48 \%(25)$. The nurse counselor was thereafter an essential member of the outreach screening team and the office-based recall team. This example demonstrates how learning at one stage of the programme influenced programme design as it matured. The programme now has an uptake rate of 90\% (AusAid Project Proposal 2012-4. Unpublished data, 2012).

The stage at which education should be introduced must be carefully considered. MoH national prevention of blindness policy often supported DR education, however concerns were raised surrounding the provision of national education before treatment services are widely available.

'It was so difficult for us, we are supposed to teach people about these causes of avoidable blindness but at the same time it was a problem because we didn't have the resources, the lasers, the people with the knowledge with the cameras' (Informant 8). 


\section{Vertical to integrated}

Guidance for establishing integrated cervical cancer screening programmes suggest there may be benefits of implementing vertical services at the start of a programme and later aim towards integration. Limited staff are trained in the early days of a programme, however, as the programme matures, a greater number of skilled and experienced staff will enable the transition towards integrated services (5).

Outreach screening in vertical programmes offered a supportive atmosphere for new graders and provided easy access to a second opinion in a setting where image transfer is not available.

'Looking at the fine detail you need another person to be near so that what you can miss another person can pick it, especially if it is an early stage diabetic changes. So that there is some counter-checking' (Informant 35).

New graders involved in the vertical programmes were expected to continue screening, between outreaches, in their normal clinical setting. However, when graders did not feel fully competent, this resulted in feelings of professional isolation.

'On the grading, [at the referral hospital] it's easy because when a nurse is asked to take images there is an ophthalmologist seated next to the ophthalmic nurse. And the ophthalmologist will be able to read and explain a few things. But where I am coming from I would be there alone to wait for the ophthalmologist to come in two weeks' (Informant 32).

\section{Geographical coverage}

Experiences from cervical cancer screening programmes suggest that chances of success are increased by initially limiting the geographical scope of a new screening service to a well-defined area, with later expansion to other regions as resources permit (5). Restriction of geographical coverage was undertaken in the Copperbelt region of Zambia, however difficulties were faced after national publicity enticed patients from outside the region, overburdening the screening camps and treatment clinics.

Information from situation analyses can assist in mapping the areas of greatest need and identifying facilities with the greatest readiness to commence programmes (5). Urban and peri-urban areas of SSA suffer the greatest prevalence of diabetes, $(26,27)$ and therefore represent areas of greatest need for DR prevention services.

\section{Adjusting the screening interval}

The ICO recommend that screening may be performed with either a yearly or two-yearly screening interval, (3) however all programmes investigated aimed to screen annually. A finding from the KDP was that despite planning to screen annually, on average patients were only attending every two years.

\section{Conclusion}

Planning for sustainable, integrated and universally accessible services requires collaboration with ministerial departments representing all health system domains, and engagement with professional, education and licensing bodies. Screening services may evolve in various formats including:

- Expansion of geographical area;
- Shortening of the screening interval;

- Progression from an opportunistic to systematic service;

- Integration of the service into the healthcare system.

The WHO Health Systems Framework was utilised in this paper as the conceptual framework for analysis, however it could serve as an invaluable tool to ensure a systematic approach to planning DR screening services. There is a need for comprehensive guidance to be provided to programme managers in resource-poor settings drawing on experiences of establishing DR screening programmes in a variety of settings. Such guidance should address the topic of policymaking at the national level and provide practical guidance on moving from policy to the actual planning, implementation, development and monitoring of a screening programme.

\section{Acknowledgements}

We are thankful to the five VISION 2020 LINK Institutions and their UK partners for their participation in data collection. We would like to thank the Sear Family Foundation for funding this project.

\section{Ethical issues}

This study was conducted in accordance with the Declaration of Helsinki and written informed consent was obtained from each participant. Institutional Review Board approval was granted by the London School of Hygiene and Tropical Medicine.

Competing interests

The authors declare that they have no competing interests.

\section{Authors' contributions}

SP carried out data collection and analysis and drafted the manuscript. All authors contributed to the design, analysis and help with subsequent versions of the manuscript. MZ participated in the coordination of the fieldwork. SP wrote the first draft of the paper. AF edited the first draft and all authors finalised and approved the paper.

\section{Authors' affiliations}

${ }^{1}$ Royal Sussex County Hospital, Brighton, UK. ${ }^{2}$ International Centre for Eye Health, International Centre for Evidence in Disability (ICED), London School of Hygiene and Tropical Medicine, London, UK. ${ }^{3}$ VISION 2020 LINKS Programme, International Centre for Eye Health, London School of Hygiene and Tropical Medicine, London, UK.

\section{References}

1. Zheng $\mathrm{Y}, \mathrm{He} \mathrm{M}$, Congdon $\mathrm{N}$. The worldwide epidemic of diabetic retinopathy. Indian J Ophthalmol 2012; 60: 428-31. doi: 10.4103/0301-4738.100542

2. Burgess PI, Msukwa G, Beare N. Diabetic retinopathy in sub-Saharan Africa: meeting the challenges of an emerging epidemic. BMC Med 2013; 11: 157 . doi: 10.1186/1741-701511-157

3. International Council of Ophthalmology (ICO). ICO Guidelines for Diabetic Eye Care [internet]. 2014. Available from: http:// www.icoph.org/resources/309/ICO-Guidelines-for-Diabetic-EyeCare.html

4. Beran D, Yudkin JS. Diabetes care in sub-Saharan Africa. Lancet 2006; 368: 1689-95. doi: 10.1016/s0140-6736(06)69704-3

5. Alliance for Cervical Cancer Prevention (ACCp). Planning and Implementing Cervical Cancer Prevention and Control Programs. Geneva: WHO; 2004.

6. World Health Organization (WHO). Everybody's Buisness. Strenthening Health Systems to Improve Health Outcomes. WHO's Framework For Action. Geneva: WHO; 2007. 
7. Blanchet K, Patel D. Applying principles of health system strengthening to eye care. Indian J Ophthalmol 2012; 60: 470-4. doi: 10.4103/0301-4738.100553

8. Pope C, Mays N. Using case studies in health services and policy research. In: Keen J, Packwood T, editors. Qualitative Research in Health Care. London: BMJ Books; 2000.

9. Baxter P, Jack S. Qualitative Case Study Methodology: Study Design and Implementation for Novice Researchers. The Qualitative Report 2008; 13: 544-59.

10. Health Knowledge. Section 5: Data Collection Methods [Internet]. 2011 [cited 2014 Nov 30]. Available from: http:// www.healthknowledge.org.uk/public-health-textbook/researchmethods/1d-qualitative-methods/section5-data-collectionmethods

11. Boyce C, Neale P. Conducting In-Depth Interviews: A Guide for Designing and Conducting In-Depth Interviews. Pathfinder International; 2006.

12. Nkomazana $\mathrm{O}$. A national survey of visual impairment in Botswana. Community Eye Heal J 2007; 20: 2020.

13. Jones S, Edwards RT. Diabetic retinopathy screening: a systematic review of the economic evidence. Diabet Med 2010; 27: 249-56. doi: 10.1111/j.1464-5491.2009.02870.x

14. Goldie SJ, Gaffikin L, Goldhaber-fiebert JD, Gordillo-tobar A, Levin C, Wright TC. Cost-Effectiveness of Cervical-Cancer Screening in Five Developing Countries. N Engl J Med 2005; 353: 2158-68. doi: 10.1056/nejmsa044278

15. Goldie SJ, Kuhn L, Denny L, Mmed O, Pollack A, Wright TC. Policy Analysis of Cervical Cancer Screening Strategies in LowResource Settings. JAMA 2001; 285: 3107-16. doi: 10.1001/ jama.285.24.3107

16. Raffle A, Gray M. Screening: Evidence and Practice. Oxford: Oxford University Press; 2007.

17. Atun RA, Bennett S, Duran A. When do vertical (stand-alone) programmes have a place in health systems? Copenhagen:
WHO Regional Office for Europe; 2008.

18. World Health Organization (WHO). Integrated health services what and why? Technical Brief No.1. Geneva: WHO; 2008.

19. UK National Screening Committee. Essential Elements in Developing a Diabetic Retinopathy Screening Programme; 2009. p. 1-75.

20. Ministry of Health and Social Welfare. United Republic of Tanzania. National Eye Care Strategic Plan 2011-2016.

21. Potter A, Debrah O, Ashun J, Blanchet K. Eye Health Systems Assessment (EHSA): Ghana Country Report, Ghana Health Service, International Centre for Eye Health, Sightsavers; 2013.

22. Melkus GD, Kurth AE, Newlin Lew K, Amoah AG, Ogedegbe G. Development and Implementation of a Diabetes Electronic Health Record in Ghana. 42nd Biennial Convention 2013 Theme: Give Back to Move Forward. Indianapolis, Indiana, USA; 2013.

23. Scanlon P. Diabetic Retinopathy Screening: Progress or Lack of Progress. In: Tombran-Tink J, Barnstable CJ, Gardner TW, editors. Ophthalmology Research: Visual Dysfunction in Diabetes. New York: Springer; 2012. p. 17-29.

24. Wormald R, Lindfield R. Screening in Ophthalmology. In: Johnson GJ, Minassian D, Weale R, West S, editors. The Epidemiology of Eye Disease. 3rd edition. London: Imperial College Press; 2012. p. 147-68.

25. Mumba M, Hall A, Lewallen S. Compliance with eye screening examinations among diabetic patients at a Tanzanian referral hospital. Ophthalmic Epidemiol 2007; 14: 306-10. doi: 10.1080/09286580701272079

26. Levy J, Jotkowitz AB. European Journal of Internal Medicine Diabetes in Africa: Screening for diabetic retinopathy. Eur $J$ Intern Med 2010; 21: 145-6. doi: 10.1016/j.ejim.2010.02.010

27. Mbanya JCN, Motala A, Sobngwi E, Assah FK, Enoru ST. Diabetes in sub-Saharan Africa. Lancet 2010; 375: 2254-66. doi: 10.1016/s0140-6736(10)60550-8 